\title{
The Effect of Fibers Type and Content on Nano Silica Concrete [Nsc]
}

\author{
K.I.M.Ibrahim \\ Construction Engineering Dept., College of Engineering at Qunfudha, Umm-Al-Qura University-KSA on \\ Sabbatical leave from higher Institute of Engineering and Technology of Kafr-EL-shiekh - Egypt
}

\begin{abstract}
The research goal is the study of fiber content and fiber type influences on NSC compressive and tensile strengths. fiber type[(steel, polypropylene and glass) and fiber content were studied. A constant water/binder equals to 0.45 and aconstant binder content $=400 \mathrm{~kg} / \mathrm{m}^{3}$ were used. the percentages of nano silica[NS] that replaced cement in this research were 0 and1.5\%. Polypropylene fiber [PPF] with $12 \mathrm{~mm}$ length and 4 dosages of $0 \%, 0.2 \%, 0.4 \%$ and $06 . \%$ are used. Glass fiber [GF] with $18 \mathrm{~mm}$ length and 4 dosages of $0 \%$, $0.2 \%, 0.4 \%$ and $06 . \%$ are also used. Steel fiber [SF] with $50 \mathrm{~mm}$ length, $0.5 \mathrm{~mm}$ diameter and 4 dosages of $0 \%$, $0.4 \%, 0.8 \%$ and $1.2 \%$ are used. The results illustrated that $1.5 \%$ NS has improvement on normal concrete compressive and tensile strengths. Increasing of SF content from $0.4 \%$ to $1.2 \%$ has significant improvement on NSC compressive and tensile strengths. PPF and GF addition caused decreasing on NSC compressive and tensile strengths.
\end{abstract}

Keywords: Nanosilica [NS] ,glass fibers, steel fibers, compressive strength and super-plasticizer.

\section{Introduction}

Many of engineering applications such as, earthquake-resistant structures, pavements, tunnel lining, industrial floors ,bridges ,pipes and hydraulic structures use fibers concrete. Because of the fibers addition, plain concrete can be transformed from not ductile material to semi ductile or ductile material. The enhancement occurred in the region of toughness and ductility. Thus fiber reinforced concrete [ FRC ] enhances the growth and formation resistance of cracks [1]. The fibers important role is the resistance of cracks formation and growth. In addition, FRC improves ultimate strain and concrete tensile strength [2-7]. The main important properties of FRC are, absorption of energy and impact resistance. These properties help FRC to play main role in technology of concrete [8-11]. Energy absorption can mainly reduce the failure risk in concrete structures, especially under live loads[12]. Nano technology is one of the most promising regions of science. Using nano materials in concrete is new revolution. Nano materials such as nano titanium oxide, NanoSilica [NS], nano alumina, which are added in concrete to improve its strength. Recently Nano Technology has been introduced in the applications of Civil Engineering. One of the most used nano material is (NS). NS has more pozzolanic nature, it posses the ability to interact with the free lime during cement hydration and forms additional C-S-H gel which gives strength, durability and impermeability to concrete. NS is one of the blending materials used to enhance the concrete properties. NSC is stickier than normal concrete owing to large surface area of NS, also it has better permeability resistance [13] NS was considered one of good blending Materials. Many searches have illustrated that adding NS to concrete leads to improvement in strength, impermeability and abrasion resistance [14-17]. Mohammad Reza Zamani Abyaneh, et al (2013) [18] have illustrated that the concrete produced with Micro-silica and NS show high of quality in their compressive strength than the concretes which only have Microsilica in their mixtures. Samples of $2 \%$ NS and 10\% Microsilica had less absorption and more resistance of electricity.

\section{Materials}

The materials which used in mixes were examined according to American Standard of Testing Materials ASTM and Egyptian Standard Specifications ESS. Basalt with maximum size $=25 \mathrm{~mm}$ and approximately flaky shape was used. Natural sand was used as a fine aggregate in this search. Ordinary cement was used and its content equal to $400 \mathrm{~kg} / \mathrm{m}^{3}$ for all concrete mixes. Supper-plasticizer was added to give the water/ cement $=0.45$ with slump equals to $(6-11) \mathrm{cm}$. Steel fiber $(\mathrm{SF})$ used of $50 \mathrm{~mm}$ length and $0.5 \mathrm{~mm}$ diameter. PPF of $12 \mathrm{~mm}$ length and glass fibers(GF) of $18 \mathrm{~mm}$ length were used. this search used NS with content of solid more than $99 \%$, its content was $1.5 \%$ replacement from cement weight. The NS was brought from Nanotech Egypt. The color of NS was white, powder appearance, spherical shape, and average size $=56 \pm 8$ nm. 


\section{Concrete Mixes Proportion}

In all, 11 mixture proportions were made, and the first mix was (without NS and fibers). The second was mix of (1.5\%NS and without fibers). There are 3 proportions of SF mixed in $1.5 \% \mathrm{NSC}$ by volume ranged from $0.4 \%$ to $1.2 \%$ and 3 proportions a of PPF mixed in $1.5 \%$ NSC by volume ranged from $0.2 \%$ to $0.6 \%$. Another 3 proportions were of GF mixed in $1.5 \%$ NSC by volume ranged from $0.2 \%$ to 0.6. All mixes proportions are showed in Table (1).

Table (1) : Concrete Mixes Proportion

\begin{tabular}{|c|c|c|c|c|c|c|c|c|c|}
\hline \multirow{2}{*}{$\begin{array}{l}\text { Mix } \\
\text { no }\end{array}$} & \multirow[t]{2}{*}{ Fiber type } & \multirow{2}{*}{$\begin{array}{l}\text { Fibers } \\
\text { content } \\
\text { Vf } \%\end{array}$} & \multicolumn{2}{|c|}{ NS content } & \multirow{2}{*}{$\begin{array}{l}\text { Cement } \\
\mathrm{kg} / \mathrm{m}^{3}\end{array}$} & \multirow{2}{*}{$\begin{array}{l}\text { Water } \\
\mathrm{kg} / \mathrm{m}^{3}\end{array}$} & \multirow{2}{*}{$\begin{array}{l}\text { Basalt } \\
\mathrm{kg} / \mathrm{m}^{3}\end{array}$} & \multirow{2}{*}{$\begin{array}{l}\text { Sand } \\
\mathrm{kg} / \mathrm{m}^{3}\end{array}$} & \multirow{2}{*}{$\begin{array}{l}\text { Super } \\
\text { plasticizer } \\
\mathrm{kg} / \mathrm{m}^{3}\end{array}$} \\
\hline & & & $\%$ & ${ }_{3} \mathrm{~kg} / \mathrm{m}$ & & & & & \\
\hline 1 & |----------- & $\mathbf{0}$ & 0 & 0 & 400 & 180 & 1224 & 612 & 4.8 \\
\hline 2 & ----------- & $\mathbf{0}$ & 1.5 & 6 & 394 & 180 & 1224 & 612 & 6 \\
\hline 3 & steel & 0.4 & 1.5 & 6 & 394 & 180 & 1224 & 612 & 12 \\
\hline 4 & steel & 0.8 & 1.5 & 6 & 394 & 180 & 1224 & 612 & 13 \\
\hline 5 & steel & 1.2 & 1.5 & 6 & 394 & 180 & 1224 & 612 & 13 \\
\hline 6 & polypropylene & 0.2 & 1.5 & 6 & 394 & 180 & 1224 & 612 & 8 \\
\hline 7 & polypropylene & 0.4 & 1.5 & 6 & 394 & 180 & 1224 & 612 & 10 \\
\hline 8 & polypropylene & 0.6 & 1.5 & 6 & 394 & 180 & 1224 & 612 & 10 \\
\hline 9 & glass & 0.2 & 1.5 & 6 & 394 & 180 & 1224 & 612 & 11.5 \\
\hline 10 & glass & 0.4 & 1.5 & 6 & 394 & 180 & 1224 & 612 & 11.5 \\
\hline 11 & glass & 0.6 & 1.5 & 6 & 394 & 180 & 1224 & 612 & 12 \\
\hline
\end{tabular}

\section{Tested Specimens}

33 cubes of $15 \mathrm{~cm}$ length and 33 cylinders of $30 \mathrm{~cm}$ height and $15 \mathrm{~cm}$ diameter, were cast for compressive and tensile strengths .Mixes of concrete were cast then mechanically compacted . The specimens of all mixes were examined by compression machine of capacity $=2000 \mathrm{KN}$.

\section{Compressive strength}

\section{Test Results}

Compressive strengths of concrete were specified at 28 days . The results are showed in Tables 2-6 and Figures 1-4. Table 2 illustrates the change of compressive strength of NSC mix , from the results it can be noticed that the compressive strength increases with $1.5 \%$ NS content.Compared with the reference concrete (without NS and fibers), the compressive strength of $1.5 \%$ NS increases of about $12.83 \%$. Table 3 and figure 1 show the change of compressive strength of steel fiber nano silica concrete( SFNSC). From the results, it can be noticed that, with increasing SF content, the compressive strength is increasing gradually and the increase is so great at the fiber volume dosage $=1.2 \%$. With comparison the control mix ( without SF but adding $1.5 \% \mathrm{~N} \mathrm{~S}$ ), the increase of compressive strength was $29.07 \%, 32.63 \%$ and $33.42 \%$ for $0.4 \%, 0.8 \%$ and $1.2 \%$ SF volume dosage respectively. Table 4 and figure 2 show the change of polypropylene fiber nano silica concrete( PPFNSC) compressive strength. From the results, it can be noticed that, with increasing fiber content, the compressive strength is decreasing and the decrease is so great at the fiber content $=0.4 \%$. Compared with the control mix ( without PPF but adding $1.5 \% \mathrm{NS}$ ) the decrease of compressive strength was $6.08 \%, 13.06 \%$ and $10.4 \%$ for $0.2 \%, 0.4 \%$ and $0.6 \%$ PPF content respectively. Table 5 and figure 3 show the change of glass fiber nano silica concrete( GFNSC) compressive strength .From the results, it can be noticed that ,with increasing fibercontent, the compressive strength is decreasing and the decrease is so great at the fiber content $=0.2 \%$. Compared with the control mix ( without GF but adding $1.5 \% \mathrm{~N} \mathrm{~S}$ ), the decrease of compressive strength was $17.13 \%, 9.5 \%$ and $7.05 \%$ for $0.2 \%, 0.4 \%$ and $0.6 \%$ GF content respectively. 
Table (2): The effect of $1.5 \%$ NS on the compressive strength $\left[\mathrm{N} / \mathrm{mm}^{2}\right]$ of concrete

\begin{tabular}{|c|c|c|c|}
\hline Fiber type & Fiber content \% & Nano silica \% & $\begin{array}{l}\text { Compressive strength }\left[\mathrm{N} / \mathrm{mm}^{2}\right] \\
\text { 28days }\end{array}$ \\
\hline 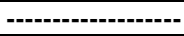 & $\mathbf{0}$ & $\mathbf{0}$ & 35.807 [reference] \\
\hline --------------- & $\mathbf{0}$ & 1.5 & $40.402[+12.83 \%]$ \\
\hline
\end{tabular}

Table (3): The effect of SF on the compressive strength [N/mm $\left.{ }^{2}\right]$ of NSC

\begin{tabular}{|l|l|l|l|}
\hline Fiber type & Fiber content \% & Nano silica \% & $\begin{array}{l}\text { Compressive strength[N/mm } \\
\text { 28days }\end{array}$ \\
\hline------------ & 0 & 1.5 & $40.402[$ control] \\
\hline \multirow{3}{*}{ steel } & 0.4 & 1.5 & $52.146[+29.07 \%]$ \\
\cline { 2 - 4 } & 0.8 & 1.5 & $53.584[+32.63]$ \\
\cline { 2 - 4 } & 1.2 & 1.5 & $53.907[+33.42 \%]$ \\
\hline
\end{tabular}

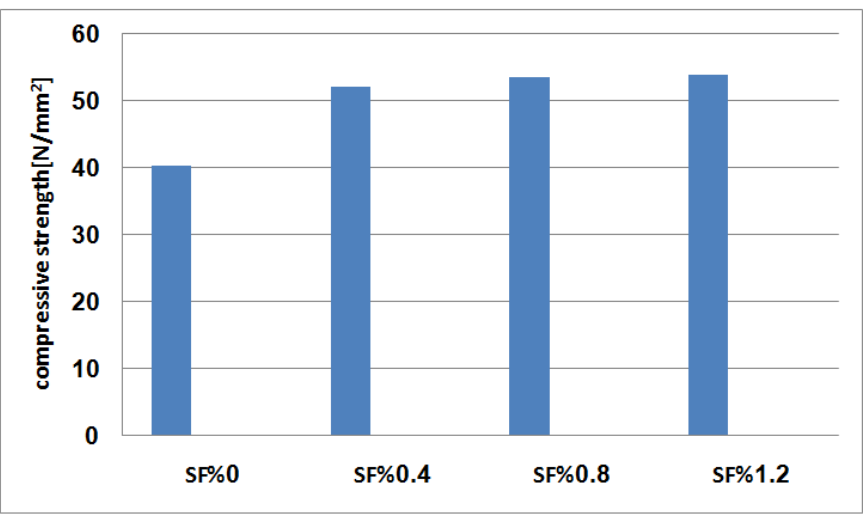

Fig.(1) The effect of SF on the compressive strength[N/mm $\left.{ }^{2}\right]$ of NSC

Table (4): The effect of PPF on the compressive strength[N/mm $\left.{ }^{2}\right]$ of NSC

\begin{tabular}{|l|l|l|l|}
\hline Fiber type & $\begin{array}{l}\text { Fiber } \\
\text { content } \%\end{array}$ & $\begin{array}{l}\text { Nano } \\
\%\end{array}$ & $\begin{array}{l}\left.\text { Compressive strength[N/mm }{ }^{2}\right] \\
\text { 28days }\end{array}$ \\
\hline------------ & 0 & 1.5 & $40.402[$ control] \\
\hline \multirow{3}{*}{ Polypropylene } & $\mathbf{0 . 2}$ & 1.5 & $\mathbf{3 7 . 9 4 4}[-6.08 \%]$ \\
\cline { 2 - 5 } & $\mathbf{0 . 4}$ & 1.5 & $35.12413 .06 \%)-[$ \\
\cline { 2 - 4 } & $\mathbf{0 . 6}$ & 1.5 & $36.2[-10.4 \%]$ \\
\hline
\end{tabular}

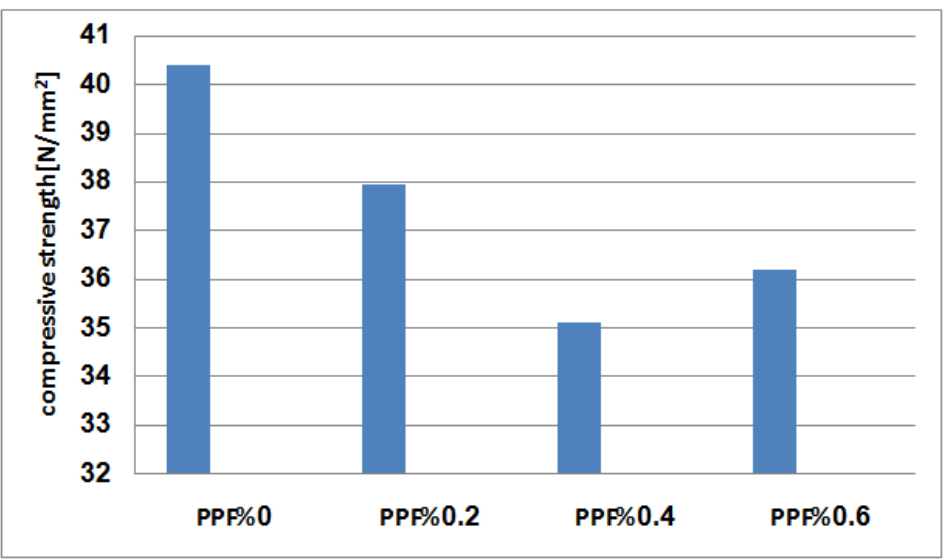

Fig.(2) The effect of PPF on the compressive strength $\left[\mathrm{N} / \mathrm{mm}^{2}\right]$ of NSC

Table (5): The effect of GF on the compressive strength[N/mm $\left.{ }^{2}\right]$ of NSC

\begin{tabular}{|c|c|c|c|}
\hline Fiber type & Fiber content $\%$ & Nano silica \% & $\begin{array}{l}\text { Compressive strength }\left[\mathrm{N} / \mathrm{mm}^{2}\right] \\
\text { 28days }\end{array}$ \\
\hline --------------- & $\mathbf{0}$ & 1.5 & 40.402[control] \\
\hline \multirow[t]{3}{*}{ Glass } & 0.2 & 1.5 & $33.48(-17.13 \%)$ \\
\hline & 0.4 & 1.5 & $36.562(-9.5 \%)$ \\
\hline & 0.6 & 1.5 & $37.553[-7.05 \%]$ \\
\hline
\end{tabular}




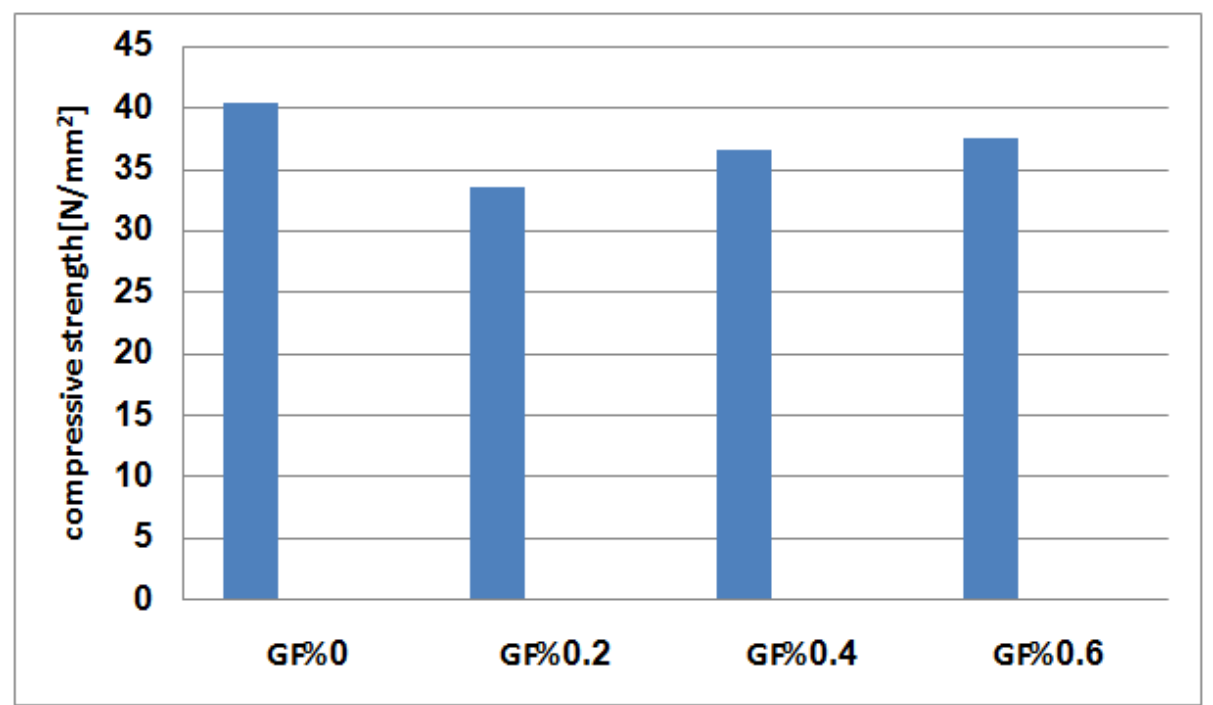

Fig.(3) The effect of GF on the compressive strength[N/mm $\left.{ }^{2}\right]$ of NSC

Table (6): Compressive strength $\left[\mathrm{N} / \mathrm{mm}^{2}\right]$ of all concrete mixes

\begin{tabular}{|l|l|l|l|}
\hline Fiber type & Fiber content \% & Nano silica \% & $\begin{array}{l}\text { Compressive strength[N/mm } \\
\text { 28days }\end{array}$ \\
\hline------------ & 0 & 0 & 35.807 \\
\hline \multirow{3}{*}{ Steel } & 0 & 1.5 & 40.402 \\
& 0.4 & 1.5 & 52.146 \\
\cline { 2 - 4 } & 0.8 & 1.5 & 53.584 \\
\cline { 2 - 4 } & 1.2 & 1.5 & 53.907 \\
\hline \multirow{5}{*}{ Polypropylene } & 0.2 & 1.5 & 37.944 \\
\cline { 2 - 4 } & 0.4 & 1.5 & 35.124 \\
\cline { 2 - 4 } & 0.6 & 1.5 & 36.2 \\
\hline \multirow{5}{*}{ Glass } & 0.2 & 1.5 & 33.482 \\
\cline { 2 - 4 } & 0.4 & 1.5 & 37.553 \\
\cline { 2 - 4 } & 0.6 & \multicolumn{2}{l}{} \\
\hline
\end{tabular}

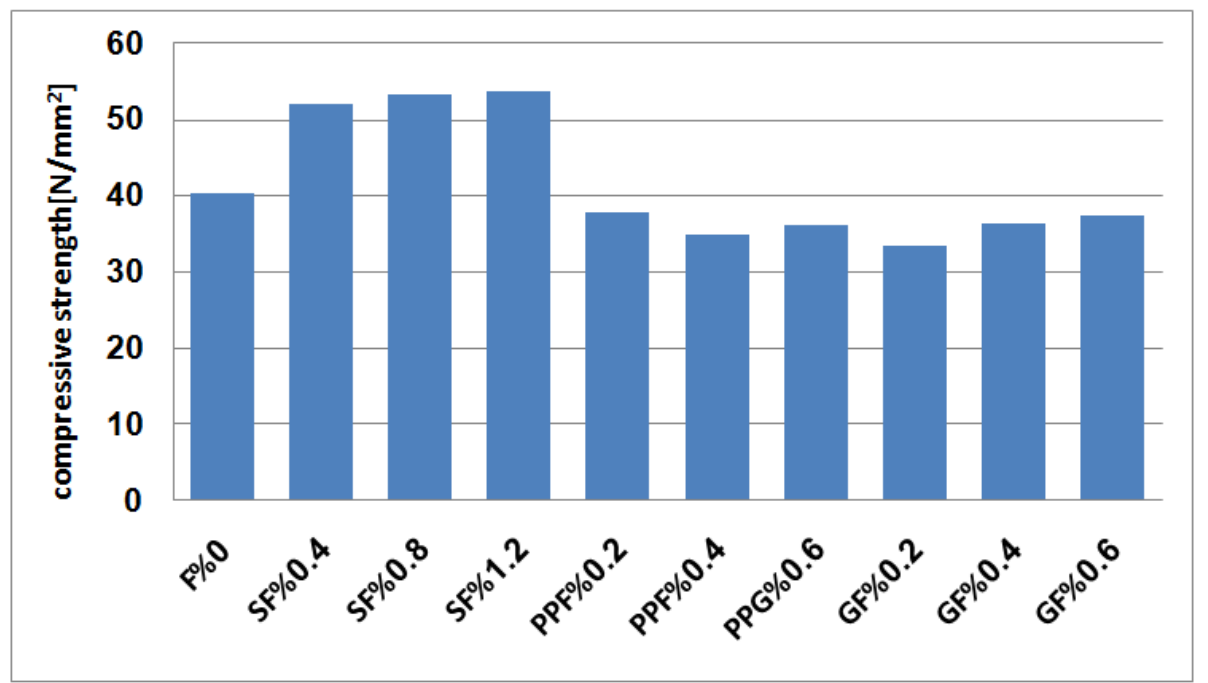

Fig.(4) Compressive strength $\left[\mathrm{N} / \mathrm{mm}^{2}\right]$ of all concrete mixes[1.5\% NS]

\section{Splitting tensile strength}

Splitting tensile strengths of concrete were specified at age $=28$ days. The test results are given in Tables7 -11 and Figures 5-8. Table 7 shows the change of tensile strength of NSC mix , from the results it can be showed that ,the tensile strength increases with $1.5 \%$ NS content. Compared with the reference mix (without NS and fibers), the tensile strength of $1.5 \%$ NS increases of about $5.68 \%$. Table 8 and figure 5 show the variation of compressive strength of steel fiber nano silica concrete( SFNSC). From the results, it can be noticed that, with increasing steel fiber content, the tensile strength is increasing gradually and the increase is so 
great at the SF content $=1.2 \%$. Compared with the control mix ( without SF but adding $1.5 \% \mathrm{~N} \mathrm{~S}$ ) the increase of tensile strength was $19.67 \%, 24.44 \%$ and $27.11 \%$ for $0.4 \%, 0.8 \%$ and $1.2 \%$ SF content respectively. Table 9 and figure 6 show the change of polypropylene fiber nano silica concrete( PPFNSC) tensile strength. From the results, it can be noticed that, with increasing PPF content, the tensile strength is decreasing gradually and the decrease is so great at the fiber content $0.4 \%$. Compared with the control mix ( without PPF but adding $1.5 \% \mathrm{~N} \mathrm{~S}$ ) the decrease of tensile strength was $11.04 \%, 15.32 \%$ and $16.65 \%$ for $0.2 \%, 0.4 \%$ and $0.6 \%$ PPF content respectively. Table 10 and figure7 show the variation of tensile strength of glass fiber nano silica concrete( GFNSC). From the results, it can be seen that,with the increase of GF content, the tensile strength is decreasing gradually and the decrease is so great at the fiber content $=0.6 \%$. Compared with the control mix ( without GF but adding $1.5 \% \mathrm{~N} \mathrm{~S}$ ) the decrease of tensile strength was $13.92 \%, 16.53 \%$ and $16.63 \%$ for $0.2 \%, 0.4 \%$ and $0.6 \%$ GF content respectively.

Table (7):The effect of $1.5 \%$ NS on the tensile strength[N/mm $\left.\mathrm{mm}^{2}\right]$ of concrete

\begin{tabular}{|l|l|l|l|}
\hline Fiber type & Fiber content \% & Nano silica \% & $\begin{array}{l}\left.\text { tensile strength[N/.mm }{ }^{2}\right] \\
\text { 28days }\end{array}$ \\
\hline-------- & 0 & 0 & $3.051[$ reference] \\
\hline------- & 0 & 1.5 & $3.224[+5.68 \%]$ \\
\hline
\end{tabular}

Table (8): The effect of SF on the tensile strength $\left[\mathrm{N} / \mathrm{mm}^{2}\right]$ of NSC

\begin{tabular}{|l|l|l|l|}
\hline Fiber type & Fiber content \% & Nano silica \% & $\begin{array}{l}\left.\text { tensile strength[N/mm }{ }^{2}\right] \\
\text { 28days }\end{array}$ \\
\hline------------ & 0 & 1.5 & $3.224[$ control] \\
\hline \multirow{3}{*}{ steel } & 0.4 & 1.5 & $3.858[+19.67 \%]$ \\
\cline { 2 - 4 } & 0.8 & 1.5 & $4.012[+24.44 \%]$ \\
\cline { 2 - 4 } & 1.2 & 1.5 & $4.098[+27.11 \%]$ \\
\hline
\end{tabular}

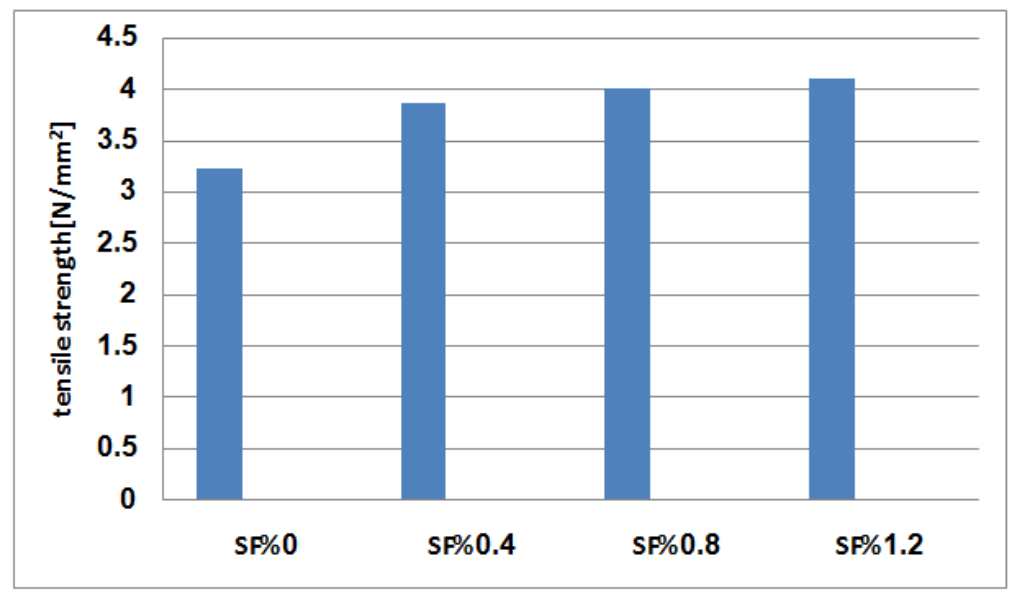

Fig.(5) The effect of SF on the tensile strength $\left[\mathrm{N} / \mathrm{mm}^{2}\right]$ of NSC

Table (9): The effect of PPF on the tensile strength[N/mm $\left.{ }^{2}\right]$ of NSC

\begin{tabular}{|c|c|c|c|}
\hline Fiber type & Fiber content \% & Nano silica \% & $\begin{array}{l}\text { tensile strength }\left[\mathrm{N} / \mathrm{mm}^{2}\right] \\
\text { 28days }\end{array}$ \\
\hline -------------- & $\mathbf{0}$ & 1.5 & $32.24[$ control] \\
\hline \multirow[t]{3}{*}{ polypropylene } & 0.2 & 1.5 & $2.868[-11.04 \%]$ \\
\hline & 0.4 & 1.5 & $2.73[-15.32 \%]$ \\
\hline & 0.6 & 1.5 & $2.687[-16.65 \%]$ \\
\hline
\end{tabular}




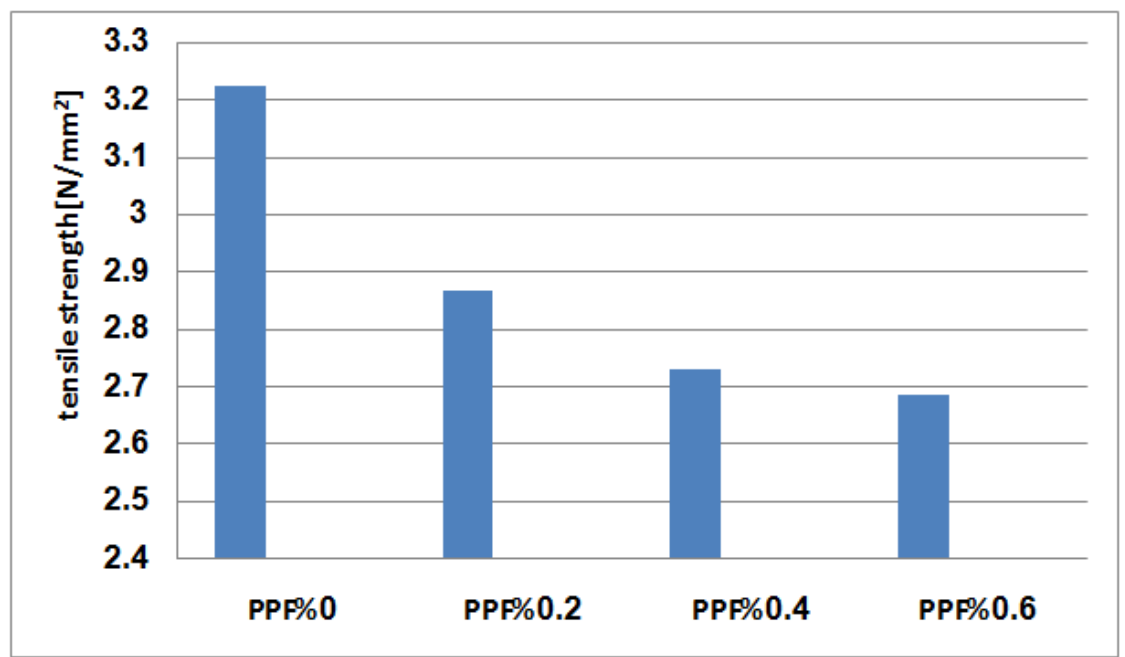

Fig.(6) The effect of PPF on the tensile strength[N/mm $\left.{ }^{2}\right]$ of NSC

Table (10): The effect of GF on the tensile strength $\left[\mathrm{N} / \mathrm{mm}^{2}\right]$ of NSC

\begin{tabular}{|l|l|l|l|}
\hline Fiber type & $\begin{array}{l}\text { Fiber } \\
\text { content } \%\end{array}$ & Nano silica \% & $\begin{array}{l}\text { tensile strength[N/mm } \\
\text { 28days }\end{array}$ \\
\hline------------ & 0 & 1.5 & $3.224[$ control] \\
\hline \multirow{3}{*}{ Glass } & 0.2 & 1.5 & $2.775[-13.92 \%]$ \\
\cline { 2 - 4 } & 0.4 & 1.5 & $2.691[-16.53 \%]$ \\
\cline { 2 - 4 } & 0.6 & 1.5 & $2.688[-16.63 \%]$ \\
\hline
\end{tabular}

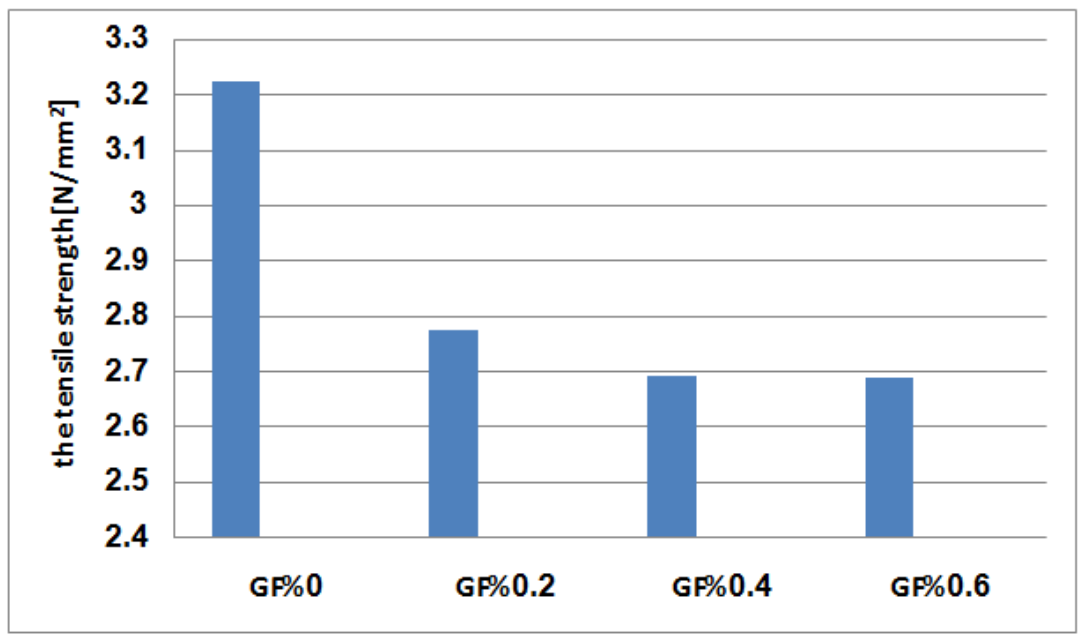

Fig.(7) The effect of GF on the tensile strength[N/mm $\left.{ }^{2}\right]$ of NSC

Table (11): tensile strength $\left[\mathrm{N} / \mathrm{mm}^{2}\right]$ of all concrete mixes

\begin{tabular}{|l|l|l|l|}
\hline Fiber type & Fiber content \% & Nano silica \% & $\begin{array}{l}\text { tensile strength[N/mm } \\
\text { 28days }\end{array}$ \\
\hline-------------- & 0 & 0 & 3.051 \\
\hline------- & 0 & 1.5 & 3.224 \\
\hline \multirow{5}{*}{ Steel } & 0.4 & 1.5 & 3.858 \\
\cline { 2 - 4 } & 0.8 & 1.5 & 4.012 \\
\cline { 2 - 4 } & 1.2 & 1.5 & 4.098 \\
\hline \multirow{5}{*}{ polypropylene } & 0.2 & 1.5 & 2.868 \\
\cline { 2 - 4 } & 0.4 & 1.5 & 2.73 \\
\cline { 2 - 4 } & 0.6 & 1.5 & 2.687 \\
\hline \multirow{5}{*}{ Glass } & 0.2 & 1.5 & 2.775 \\
\cline { 2 - 4 } & 0.4 & 1.5 & 2.691 \\
\cline { 2 - 4 } & 0.6 & 2.688 \\
\hline
\end{tabular}




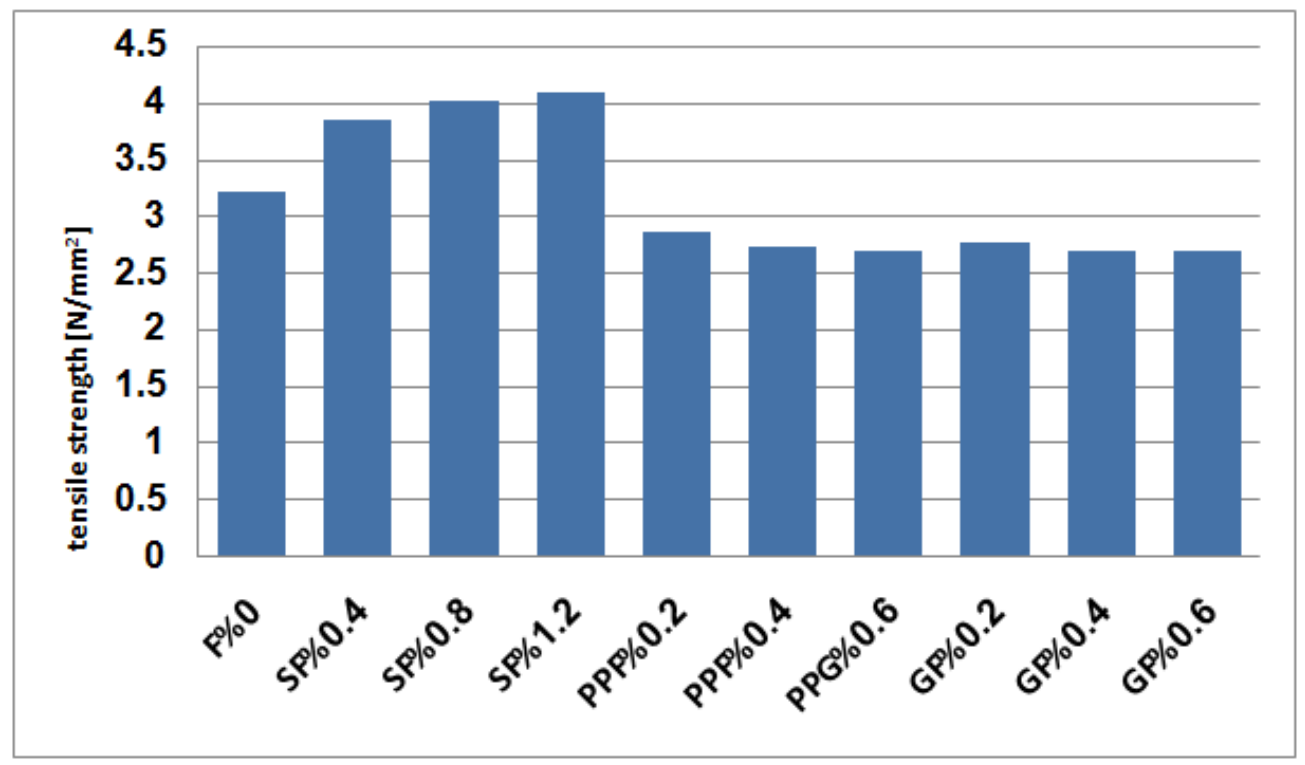

Fig.(8) Tensile strength $\left[\mathrm{N} / \mathrm{mm}^{2}\right]$ of all concrete mixes[1.5\%NS]

\section{Conclusions}

1. All types of fibers appeared to have an adverse influence on the workability of NSC.

2. Nano silica has small improvement on the compressive strength and splitting tensile strength of normal concrete. The increase in compressive and tensile strength was $12.83 \%$ and $5.68 \%$ for $1.5 \%$ of NS replaced by cement respectively.

3. The compressive and tensile strength of NSC increase with increasing of steel fiber content compared with control concrete [1.5\% NS]. The increase in compressive strength was $29.07 \%, 32.63 \%$ and $33.42 \%$ for steel fiber content $0.4 \%, 0.8 \%$ and $1.2 \%$ respectively as was $19.67 \%, 24.44 \%$ and $27.11 \%$ for tensile strength.

4. It was found that the increase in compressive and tensile strengths is directly proportional to the SF content.

5. The addition of PPF and GF caused an adverse influence on the compressive and tensile strengths of $1.5 \%$ NSC.

6. The compressive and tensile strength of NSC decrease with increasing in PPF content compared with control concrete $[1.5 \% \mathrm{NS}]$. The decrease in compressive strength was $6.08 \%, 13.06 \%$ and $10.4 \%$ for PPF content $0.2 \%, 0.4 \%$ and $0.6 \%$ respectively as was $11.04 \%, 15.32 \%$ and $16.65 \%$ for tensile strength.

7. The compressive and tensile strengths of NSC decrease with increasing of GF content compared with control concrete [1.5\% NS]. The decrease in compressive strength was $17.13 \%, 9.5 \%$ and $7.05 \%$ for GF volume fraction $0.2 \%, 0.4 \%$ and $0.6 \%$ respectively as was $13.92 \%, 16.53 \%$ and $16.63 \%$ for tensile strength.

8. It was observed that the decrease in tensile strength are directly proportional to the GF and PPF contents.

References

[1]. P. Di Maida, E. Radi , C. Sciancalepore, and F. Bondioli . Pullout behavior of polypropylene macro-synthetic fibers treated with nanosilica. Construction and Building Materials 2015; 82: 39-44.

[2]. Mohammad Haji Sotoudeh and Mostafa Jalal. Effects of waste steel fibers on strength and stress-strain behavior of concrete incorporating silica nanopowder .Indian Journal of Science and Technology $2013 ; 6(11): 5411-5417$.

[3]. Ding Y, and Kusterle W. Compressive stress-strain relationship of steel fiber-reinforced concrete at early age. Cement and Concrete Research 2000; 30(10): 1573-1579.

[4]. Sorooshian P, and Bayasi Z . Fiber type effects on the performance of steel fiber reinforced concrete. ACI Materials Journal 1991 Technical Paper ; 88(2): 53-60.

[5]. Jalal M . Compressive strength enhancement of concrete reinforced by waste steel fibers utilizing nano SiO2. Middle-East Journal of Scientific Research 2012; 12(3): 382-391.

[6]. Soroushian P. Secondary reinforcement adding cellulose fibers. ACI Concrete Int.1986:28-38.

[7]. Park Seung Hun, Kim Dong Joo, Ryu Gum Sung, Koh Kyung Taek. Tensile behavior of ultra high performance hybrid fiber reinforced concrete. Cement Concrete Composites 2012;34:172-84.

[8]. Kang Su-Tae, Lee Yun, Park Yon-Dong, Kim Jin-Keun. Tensile fracture properties of an ultra high performance fiber reinforced concrete (UHPFRC) with steel fiber. Compos Structure 2010;92:61-71.

[9]. Olivito RS, Zuccarello FA. An experimental study on the tensile strength of steel fiber reinforced concrete. Composites: Part B 2010;41:246-255.

[10]. Meddah Mohammed Seddik, Bencheikh Mohamed. Properties of concrete reinforced with different kinds of industrial waste fiber materials. Construction Build. Mater. 2009;23:3196-205. 
[11]. Bencardino F, Rizzuti L, Spadea G, Swamy RN. Experimental evaluation of fiber reinforced concrete fracture properties. Composites: Part B 2010;41:17-24.

[12]. Morteza H. Beigi, Javad Berenjian , Omid Lotfi Omran, Aref Sadeghi Nik , and Iman M. Nikbin. An experimental survey on combined effects of fibers and nanosilica on the mechanical, rheological, and durability properties of self-compacting concrete, Materials and Design 2013; 50: 1019-1029.

[13]. Taoji ,"Preliminary study of water permeability and micro structure of concrete incorporating Nano silica". 2005 cement and concrete research 35, pp1943-1947.

[14]. Qing Ye, Zenan Zhang, Deyu Kong, Rongshen Chen . Influence of nano-SiO2 addition on properties of hardened cement paste as compared with silica fume. Construction and Building Materials $200721: 539-545$.

[15]. Hui, L., Mao-hua, Z. \& Jin-ping, O. Abrasion resistance of concrete containing nano-particles for pavement. Wear 2006 ; 260 : $1262-1266$.

[16]. Byung-wan, J., Chang-hyun, K., Ghi-ho, T. \& Jong-bin, P. Characteristics of cement mortar with nano-SiO2 particles. Construction and Building Materials 2007 ; 21: 1351-1355.

[17]. Jeng-ywan, S., Ta-peng, C. \& Tien-chin, H. . Effect of nanosilica on characterization of Portland cement composite. Materials Science and Engineering A 2006; 424: 266-274.

[18]. Mohammad Reza Zamani Abyaneh, Alireza Mehran, Seyed Mohammad Mahdi Hoseini. Effects of Nano-Silica on Permeability of Concrete and Steel Bars Reinforcement Corrosion. Australian Journal of Basic and Applied Sciences2013; 7(2): 464-467,. 